\title{
State-Level Alcohol Environments and Sexual Identity Disparities in Binge Drinking in the Behavioral Risk Factor Surveillance System
}

\author{
Naomi Greene, PhD, MPH, ${ }^{1}$ Renee M. Johnson, $\mathrm{PhD},{ }^{2}$ Danielle German, PhD, ${ }^{1}$ \\ Joanne Rosen, JD, ${ }^{3}$ and Joanna E. Cohen, $\mathrm{PhD}^{1}$
}

\begin{abstract}
Purpose: Binge drinking disparities by sexual identity are well documented. Stronger alcohol policy environments reduce binge drinking in the general population. We examined whether state-level alcohol policy environments have the same association with binge drinking among lesbian, gay, and bisexual (LGB) adults as among heterosexual adults.

Methods: Binge drinking, sexual identity, and demographic characteristics were extracted from the 2015 to 2018 Behavioral Risk Factor Surveillance System. The strength of the alcohol policy environment was measured by using the Alcohol Policy Scale (APS) score. We estimated the association between APS score and binge drinking by using logistic regression and included an interaction term between APS score and sexual identity.

Results: The interaction between APS score and sexual identity was not significant, and findings differed between women and men. Among women, a higher APS score was associated with lower odds of binge drinking (adjusted odds ratio [aOR]: 0.96, 95\% confidence interval [CI]: 0.94-0.99). Differences in binge drinking by sexual identity remained after adjusting for individual and state-level factors (e.g., the percentage of LGB adults in the state). Compared with heterosexual women, the odds of binge drinking were $43 \%$ higher (aOR: $1.43,95 \% \mathrm{CI}$ : 1.17-1.75) among lesbian women and 58\% higher (aOR: 1.58, 95\% CI: 1.40-1.79) among bisexual women. A higher APS score was not associated with binge drinking among men.

Conclusion: Stronger state-level alcohol policy environments were associated with lower binge drinking among women. Lesbian and bisexual women were still more likely to engage in binge drinking compared with heterosexual women even in states with stronger alcohol policy environments.
\end{abstract}

Keywords: alcohol policy environment, Behavioral Risk Factor Surveillance System, binge drinking, health disparities, LGB, multilevel models

\section{Introduction}

$\mathbf{I}^{2}$ N 2018, MORE THAN 39 MILLION U.S. adults engaged in binge drinking, ${ }^{1}$ defined as $4+$ or $5+$ alcoholic drinks for women or men on one occasion. ${ }^{2}$ Binge drinking results in injuries, suicide, interpersonal violence, and cancer. $^{3}$ Although men in the United States are more likely to engage in binge drinking than women, over the past decade the gap between women and men has narrowed as a higher proportion of women are engaging in binge drinking., 4

Further, there are differences in binge drinking prevalence by sexual identity, which are more pronounced among women than men. Data from the National Survey on Drug
Use and Health show that for lesbian, gay, and bisexual (LGB) adults, the prevalence of binge drinking is $36.1 \%$ compared with $26.7 \%$ among heterosexual adults, a statistically significant difference. ${ }^{6}$ Among women, $38 \%$ of lesbian and bisexual women binge drink compared with $21 \%$ of heterosexual women, a statistically significant difference. ${ }^{6}$ Moreover, sexual minority women (whether defined by identity, attraction, or behavior) are more likely to engage in high-intensity binge drinking (i.e., $8+$ drinks in a single day) compared with exclusively heterosexual women. ${ }^{7}$ A population-based study showed that gay and bisexual men have increased odds of excessive alcohol use compared with heterosexual men, ${ }^{8}$ whereas another study showed no 
significant difference between sexual minority and heterosexual men. ${ }^{9}$ The "gender paradox" is the finding that there is a larger gap in alcohol use and alcohol-related harms between LGB and heterosexual women compared with the smaller gap between gay/bisexual and heterosexual men. ${ }^{10}$ This paradoxical finding underlies the importance of examining differences in binge drinking disparities by sexual identity separately for women and men.

Most studies examining the determinants of binge drinking differences between sexual minority and heterosexual populations focus on individual and interpersonal factors. Links between hazardous alcohol use among sexual minority adults and experiences of minority stressors include perceived discrimination, ${ }^{11,12}$ and interpersonal violence. ${ }^{13,14}$ Differences in community norms around drinking, including differences in where and with whom sexual minority and heterosexual individuals drink, ${ }^{15,16}$ the role that alcohol plays in the LGBT community and identity development, ${ }^{17,18}$ and the use of alcohol to cope with general and minority stressors, ${ }^{19}$ have also been studied. However, factors at all levels of the social ecology (individual, interpersonal, community, and policy) shape differential risk for binge drinking, yet few studies have examined policy-level factors and their relationship with differences in binge drinking across sex and sexual orientation.

Alcohol policies are strongly related to population-level alcohol consumption in the general population. ${ }^{20-22}$ Broadly, alcohol policies reduce physical availability of alcohol products, increase their price, and make it more expensive to use alcohol excessively. ${ }^{23} \mathrm{~A}$ few specific alcohol policies reduce binge drinking and alcohol-related harms at the population level, including increased alcohol taxes ${ }^{24}$ regulations on the amount of alcohol outlets in a given area (i.e., alcohol outlet density), ${ }^{25}$ and limitations to days and hours of sale for alcohol products. ${ }^{26}$ However, a recent study examining the effect of beverage-specific taxes on alcohol consumption and alcohol-related harms found that this type of alcohol policy was protective for some subgroups, primarily African American women, but not all subgroups leading the authors to call for future research on the association between alcohol policies and alcohol consumption across subgroups. ${ }^{27}$

Nevertheless, individual alcohol policies are not enacted and implemented in a vacuum. Therefore, alcohol policy researchers have developed a tool to measure the strength of the alcohol policy environment. The Alcohol Policy Scale (APS) is a composite policy measure that assesses the combined strength of multiple individual alcohol policies functioning within a jurisdiction, primarily at the state level. ${ }^{20}$ Stronger alcohol policy environments are associated with reduced individual-level binge drinking in the general population and among certain subgroups, but not others. ${ }^{21}$ However, similar to studies examining individual alcohol policies, few studies have examined whether the alcohol policy environment is associated with lower binge drinking among sexual minority individuals or wider differences in binge drinking between sexual minority and heterosexual populations. One study from the tobacco policy literature indicates that stronger tobacco policy environments are associated with narrower differences in tobacco use between sexual minority and heterosexual adults. ${ }^{28}$ Given that there are limited studies examining the influence of policy factors on binge drinking among sexual minority adults and the indication that policy environments related to tobacco use may reduce disparities, the current study seeks to fill an important gap in the literature on how alcohol policy environments are related to binge drinking among sexual minority populations.

The purpose of this study was to examine the association between the state-level alcohol policy environment and individual-level binge drinking comparing LGB and heterosexual adults in the United States. The primary aim was to examine whether the association between the alcohol policy environment and binge drinking is the same for LGB and heterosexual adults. A sub-aim of this study was to explore whether the alcohol policy environment is associated with differences in binge drinking risk between LGB and heterosexual adults. We hypothesized that the association between the state-level alcohol policy environment and binge drinking would be the same for LGB adults compared with heterosexual adults given that the alcohol policies included in the composite policy score are not targeted at any specific sexual identity group and are, theoretically, equitably implemented across a state's population.

\section{Methods}

\section{Data}

We used the 2015-2018 Behavioral Risk Factor Surveillance System (BRFSS), a repeated cross-sectional survey overseen by the Centers for Disease Control and Prevention (CDC). Each U.S. state, the District of Columbia, and U.S. territories conduct telephone interviews using landlines and cellphones. Multistage sampling and random digit dialing are used to produce nationally and sub-nationally representative samples of U.S. adults $18+$ years. ${ }^{29}$ Inclusion of cellphones and new weighting methods since 2011 have improved representativeness of the target population. ${ }^{30}$ Jurisdictions draw on items included in the core BRFSS instruments to enhance comparability across sites. Jurisdictions may also include $\mathrm{CDC}$-approved optional modules, which are questions that have been cognitively tested. ${ }^{29}$ The sexual orientation and gender identity (SOGI) module is an optional CDC module that collects information about participants' SOGI. We restricted the analysis sample to the 35 U.S. states that used the SOGI module in at least 1 year during the study period (2015-2018). Three states used the module in only 1 year; 10 states in 2 years; 10 states in 3 years; and 12 states for all 4 years. The Johns Hopkins Bloomberg School of Public Health Institutional Review Board determined that this study was exempt, because it uses secondary publicly available data sources.

\section{Measures}

We ascertained sexual identity by using the question on the SOGI module. Participants were asked "Do you consider yourself to be?" with the following response options: Straight (i.e., heterosexual), Lesbian or Gay, Bisexual, or Something Else. People who identified as "something else," or who responded, "Don't Know" or "Refused," or were missing responses for this question were excluded from the analysis (women: 15.39\%; men: 16.29\%). Binge drinking was measured by using the following question. Participants were asked: "Considering all types of alcoholic 
beverages, how many times during the past 30 days did you have $\mathrm{X}[X=5$ for men, $X=4$ for women $]$ or more drinks on an occasion." Participants who answered that they engaged in this behavior one or more times were classified as binge drinkers. $^{2}$

We measured the strength of the alcohol policy environment by using the APS score, which measures both the presence of multiple alcohol policies and their degree of implementation within each state. The development of the APS score has been discussed in detail elsewhere. ${ }^{20}$ Briefly, Boston University researchers convened a Delphi panel of alcohol policy experts. The panel agreed on 29 policies believed to reduce binge drinking at the population level. The expert panel rated each policy on a scale of 1 (low efficacy) to 5 (high efficacy) for how effective each policy is at reducing binge drinking. The final efficacy rating for each alcohol policy is the average of efficacy ratings across the members of the Delphi panel. Then, the researchers developed implementation ratings for each policy. APS scores are calculated by multiplying the implementation rating by the efficacy rating for each policy implemented in a state in a given year and then summed across all policies. ${ }^{20}$

The APS score is calculated annually for each state. We used 2014-2017 APS scores for this analysis. As with previous studies, the APS scores were rescaled to be between $0 \%$ and $100 \%$ by dividing each state's score by the highest possible score and multiplying by $100 .^{21,22}$ The APS scores were then divided by 10 so that a 1 unit increase in the beta coefficient represented a 10 percentage point increase in APS score. Higher alcohol policy scores reflect stronger alcohol policy environments where many effective individual alcohol policies have been enacted and implemented such that alcohol products are less available, accessible, and affordable, and penalties for violating alcohol laws are more severe.

We selected the following contextual factors a priori based on previous studies on alcohol policy environments: percentage of the state population across age, sex, and race/ethnicity, median household income, law enforcement officers per capita, percentage of the state living in urban areas, prevalence of Catholic religious affiliation, and state region. ${ }^{21,22}$ Differences in state-level demographic characteristics ${ }^{31}$ and geography (including differences in region and urban/rural classification) ${ }^{32}$ offer competing explanations of differences in population-level binge drinking and may confound the associations under study. Moreover, differences in law enforcement per capita crudely measure a state's ability to enforce certain alcohol policies. ${ }^{33}$ A previous study showed a strong positive correlation between the prevalence of Catholics in a state and a state's binge drinking prevalence and no association between the overall prevalence of any religious affiliation and binge drinking. ${ }^{34}$ Having a higher proportion of LGB individuals could be a proxy for greater access to LGB community spaces for LGB individuals.

Information about the percentage of the population across age, sex, and race/ethnicity came from the American Community Survey. ${ }^{35-38}$ For 2015, 2016, and 2017, we used 5 -year estimates. The latest data for 2018 were 1-year estimates. Specific state-level demographic variables included the percentage of the population age 21 years and older (i.e., legal drinkers), the percentage of the population that are adult males, and the percentage of the population that is non-Hispanic White. The number of law enforcement officers per capita came from the Federal Bureau of Investigation Uniform Crime Reporting Statistics. ${ }^{39}$ The 2010 Census provided information about the percentage of a state's population living in urban areas. ${ }^{40,41}$ Religious affiliation was measured as the number of Catholic adherents per 1000 population, from the U.S. Religion Census Religious Congregations and Membership Study. ${ }^{42}$ State region (i.e., Northeast, Midwest, South, West) is determined by the U.S. Census Bureau. ${ }^{43}$ Data from the Williams Institute provided the estimated number of LGB adults (18+ years) for each state using the 2017 Gallup Tracking poll. ${ }^{44}$ We divided the estimated number of LGB adults by the 2017 state population 5-year estimates to obtain the percentage of LGB adults in each state.

Individual demographic characteristics came from the BRFSS. These included age (18-24, 25-34, 35-44, 45-54, 55-64, 65+ years), sex (female, male), race/ethnicity (nonHispanic White, non-Hispanic Black, Hispanic, non-Hispanic other race, non-Hispanic multiracial), education (less than high school, high school graduate, some college, college graduate), household income $(<\$ 15 \mathrm{~K} ; \$ 15-24,999 ; \$ 25-$ 34,999; \$35-49,000; $\$ 50 \mathrm{~K}$ plus), and relationship status (married, divorced, widowed, separated, never married, member of unmarried couple).

\section{Statistical analyses}

All analyses were stratified by sex. We used descriptive statistics to analyze individual characteristics and statelevel factors. Descriptive statistics for individual characteristics were calculated in Stata 16 by using svy set commands to account for the BRFSS complex survey design.

Logistic regression was used to estimate the association between APS score, sexual identity, and individual-level binge drinking. The APS scores were lagged by 1 year to account for full implementation of any new alcohol laws enacted in the prior year. We examined whether the association between APS score and binge drinking differed across sexual identity by including an interaction term in the logistic regression models. To explore our sub-aim, we treated sexual identity as the primary independent variable, the APS score as the secondary independent variable, and included all the individual and state-level covariates in the model. We conducted this analysis in SAS 9.4 by using PROC SURVEYLOGISTIC, which accounts for the BRFSS' complex survey design using design weights that provide accurate standard errors. Covariates were grouped by whether they measured individual characteristics (i.e., age, race/ethnicity, income, education, relationship status), state-level characteristics (i.e., population demographics by age, sex, race, sexual identity; urban population; percent Catholic), state enforcement capacity (i.e., law enforcement officers per capita), and state geography (i.e., Census region). We present models accounting for individual characteristics, state-level characteristics, state enforcement capacity, and state geography as well as all topic areas to thoroughly account for and rule out confounding. All models accounted for secular trends in binge drinking prevalence by including survey year.

\section{Results}

The sample included 435,921 women and 339,660 men. Lesbian and bisexual women were younger, more likely to 
identify as non-Hispanic Black, and more likely to have never been married compared with heterosexual women (Table 1). Bisexual women (15.4\%) were most likely to have household incomes less than $\$ 15,000$ compared with both heterosexual women $(11.5 \%)$ and lesbian women $(12.7 \%)$. Gay and bisexual men were younger and more likely to have never been married compared with heterosexual men (Table 2). Gay men $(37.9 \%)$ were most likely to have graduated from college followed by heterosexual men $(26.5 \%)$ and bisexual men (22.2\%). However, gay (11.4\%) and bisexual men (11.9\%) were more likely than heterosexual men $(7.9 \%)$ to have household incomes less than $\$ 15,000$.
The APS scores did not vary widely from 2014 to 2017 (Fig. 1). Pennsylvania and Oklahoma were outliers with very strong alcohol policy environments. Pooled data from 2014 to 2017 show that, overall, states had moderately strong alcohol policy environments (Table 3). From 2015 to 2018, states varied substantially in religious affiliation, percentage of the population living in urban areas, percentage of the population that is non-Hispanic White, and median household income (Supplementary Table S1). Most states were in the Southern region.

The statistical test for interaction between state APS score and sexual minority identity was not statistically significant among women (lesbian: $p=0.789$; bisexual: $p=0.204$ ).

Table 1. Demographic Characteristics by Sexual Identity Among Women in the Behavioral Risk Factor Surveillance System, 2015-2018

\begin{tabular}{|c|c|c|c|}
\hline Heterosexual & Lesbian & Bisexual & All women \\
\hline $\mathrm{N}^{\mathrm{a}}=421,737$ & $\mathrm{~N}^{\mathrm{a}}=5079$ & $\mathrm{~N}^{\mathrm{a}}=9105$ & $\mathrm{~N}^{\mathrm{a}}=435,921$ \\
\hline $\begin{array}{c}\text { Weighted \% } \\
(95 \% \text { CI) }\end{array}$ & $\begin{array}{l}\text { Weighted \% } \\
(95 \% \text { CI) }\end{array}$ & $\begin{array}{l}\text { Weighted \% } \\
(95 \% \text { CI) }\end{array}$ & $\begin{array}{c}\text { Weighted \% } \\
\quad(95 \% \text { CI) }\end{array}$ \\
\hline
\end{tabular}

Age group, years

$18-24$

$25-34$

$35-44$

45-54

$55-64$

$65+$

Race/ethnicity

White, $\mathrm{NH}$

Black, NH

Hispanic

Other race, $\mathrm{NH}$

Multiracial, $\mathrm{NH}$

Education

Less than high school

High school graduate

Some college

College graduate

Income level

$<\$ 15 \mathrm{~K}$

$\$ 15,000-24,999$

$\$ 25,000-34,999$

$\$ 35,000-49,999$

$\$ 50 \mathrm{~K}+$

$10.0(9.8-10.3) \quad 16,071 \quad 21.8(19.1-24.8)$

$14.6(14.3-14.8) \quad 34,277 \quad 19.3(17.1-21.6)$

$15.7(15.5-16.0) \quad 45,483$

$14.8(12.9-16.9)$

$48536.7(34.8-38.6) \quad 2044 \quad 11.9(11.7-12.1) \quad 24,532$

$17.6(17.3-17.8) \quad 66,640$

$18.3(16.4-20.4)$

$69830.6(28.9-32.4)$

$63214.8(13.5-16.1)$

18.3 (18.0-18.5) 95,162 $14.5(12.9-16.1) 1233$

$8.2(7.3-9.2)$

$5.1(4.5-5.7)$

23.9 (23.6-24.1) $164,104 \quad 11.4(9.6-13.4) \quad 1007 \quad 4.7(4.1-5.3)$

$65.4(65.1-65.7) \quad 327,164 \quad 62.3(59.1-65.4) \quad 3799 \quad 62.3$ (60.4-64.2)

$12.7(12.5-12.9) \quad 37,050 \quad 15.9(13.7-18.3) \quad 437 \quad 13.3(12.0-14.8)$

$14.6(14.3-14.9) \quad 26,325 \quad 13.4(11.0-16.1) \quad 349 \quad 14.7(13.3-16.3)$

$\begin{array}{lllll}6.0(5.8-6.3) & 17,020 & 6.0(4.2-8.5) & 220 & 6.0(5.1-7.0)\end{array}$

$\begin{array}{lllll}1.3(1.2-1.3) & 8867 & 2.5(1.8-3.3) & 207 & 3.7(3.1-4.3)\end{array}$

$12.0(11.8-12.3) \quad 27,250 \quad 10.3(8.5-12.5)$

$25613.0(11.6-14.6)$

$239616.8(16.6-17.0) \quad 49,100$

$154016.0(15.8-16.3) \quad 57,728$

$111816.7(16.4-16.9) \quad 80,440$

$921 \quad 16.8(16.6-17.0) \quad 111,024$

$108621.8(21.6-22.0) \quad 192,220$

$27.1(26.8-27.4) \quad 113,44425.3(22.6-28.1) \quad 103128.3 \quad(26.6-30.1) 229126.9(26.6-27.1) \quad 139,427$

32.8 (32.5-33.1) $120,885 \quad 31.7(29.0-34.6) \quad 1291 \quad 37.3 \quad(35.4-39.2) \quad 2966 \quad 32.0(31.7-32.2) \quad 144,858$

$28.1 \quad(27.9-28.4) \quad 159,15032.7(30.3-35.2) 249421.4(20.1-22.7) 318228.0(27.8-28.2) \quad 190,806$

$11.5(11.2-11.7) \quad 36,488 \quad 12.7(10.8-14.8) \quad 492 \quad 15.4(13.9-16.9) \quad 1146 \quad 12.3(12.1-12.5) \quad 46,625$

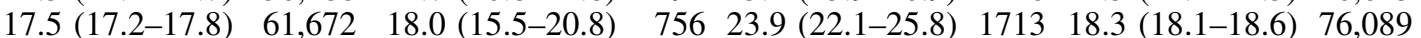

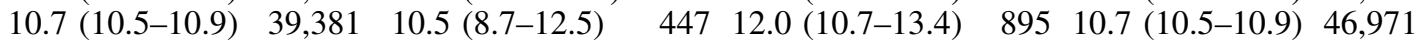

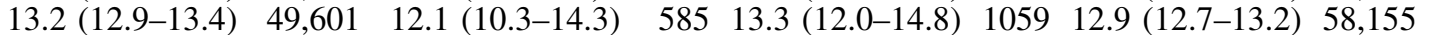

Relationship status

Married

Divorced

Widowed

Separated

Never married

Member of unmarried couple
$47.1(46.8-47.5) \quad 163,559 \quad 46.7(43.6-49.8) 2246 \quad 35.4(33.5-37.5) \quad 2800 \quad 45.7(45.4-46.0) \quad 189,608$

$\begin{array}{lllllllll}51.1 & (50.8-51.4) & 207,839 & 28.4(26.0-30.9) & 1625 & 23.6(22.1-25.2) & 2648 & 49.1(48.8-49.4) & 246,976\end{array}$

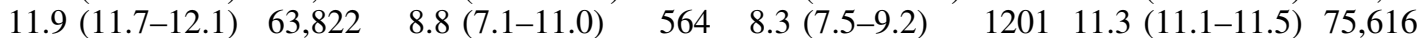

$\begin{array}{llllllll}10.7(10.5-10.9) & 74,711 & 2.8(2.1-3.8) & 213 & 2.7(2.3-3.2) & 515 & 10.0(9.9-10.2) & 88,390\end{array}$

$\begin{array}{llllllll}2.7(2.6-2.8) & 9182 & 2.4(1.8-3.2) & 98 & 4.0(3.3-4.8) & 376 & 2.8(2.7-2.9) & 11,961\end{array}$

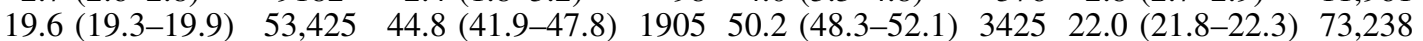

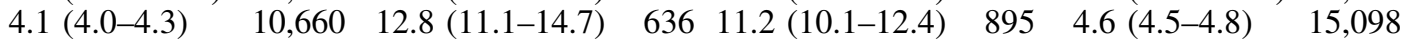

The sample was restricted to states that used the SOGI module, which included: CA, CO, CT, DE, FL, GA, HI, ID, IL, IN, IA, KS, KY, LA, MD, MA, MN, MS, MO, MT, NV, NY, NC, OH, OK, PA, RI, SC, TN, TX, VT, VA, WA, WI, and WV.

${ }^{\mathrm{a}}$ Unweighted sample size.

CI, confidence interval; SOGI, sexual orientation and gender identity; $\mathrm{NH}$, non-Hispanic. 
Table 2. Demographic Characteristics by Sexual Identity Among Men in the Behavioral Risk Factor Surveillance System, 2015-2018

\begin{tabular}{|c|c|c|c|c|c|c|c|c|}
\hline & \multicolumn{2}{|c|}{ Heterosexual } & \multicolumn{2}{|l|}{ Gay } & \multicolumn{2}{|l|}{ Bisexual } & \multicolumn{2}{|l|}{ All men } \\
\hline & \multicolumn{2}{|c|}{$\mathrm{N}^{\mathrm{a}}=327,574$} & \multicolumn{2}{|l|}{$\mathrm{N}^{\mathrm{a}}=7158$} & \multicolumn{2}{|l|}{$\mathrm{N}^{\mathrm{a}}=4928$} & \multicolumn{2}{|c|}{$\mathrm{N}^{\mathrm{a}}=339,660$} \\
\hline & $\begin{array}{c}\text { Weighted \% } \\
(95 \% \text { CI })\end{array}$ & $\mathrm{n}^{\mathrm{a}}$ & $\begin{array}{c}\text { Weighted \% } \\
(95 \% \text { CI })\end{array}$ & $\mathrm{n}^{\mathrm{a}}$ & $\begin{array}{c}\text { Weighted \% } \\
(95 \% \text { CI })\end{array}$ & $\mathrm{n}^{\mathrm{a}}$ & $\begin{array}{c}\text { Weighted \% } \\
(95 \% \text { CI })\end{array}$ & $\mathrm{n}^{\mathrm{a}}$ \\
\hline \multicolumn{9}{|l|}{ Age group, years } \\
\hline $18-24$ & $12.2(12.0-12.5)$ & 20,000 & $17.7(15.8-19.7)$ & 713 & $30.3(27.8-33.0)$ & 919 & $13.3(13.1-13.5)$ & 28,051 \\
\hline $25-34$ & $16.2(15.9-16.5)$ & 32,903 & $22.5(20.7-24.5)$ & 1081 & $22.0(19.8-24.3)$ & 851 & $18.2(17.9-18.4)$ & 46,265 \\
\hline $35-44$ & $16.4(16.2-16.7)$ & 38,224 & $14.3(12.8-15.9)$ & 788 & $12.1(10.4-14.1)$ & 497 & $16.8(16.5-17.0)$ & 48,802 \\
\hline $45-54$ & $17.6(17.3-17.8)$ & 53,953 & $19.8(18.1-21.6)$ & 1437 & $11.9(10.4-13.6)$ & 664 & $17.1(16.8-17.3)$ & 66,472 \\
\hline $55-64$ & $17.8(17.5-18.0)$ & 74,162 & $15.4(13.9-16.9)$ & 1609 & $12.3(10.8-14.0)$ & 872 & $16.5(16.3-16.7)$ & 88,336 \\
\hline $65+$ & $19.8(19.6-20.0)$ & 108,332 & $10.4(9.4-11.4)$ & 1530 & $11.4(10.0-12.9)$ & 1125 & $18.2(18.0-18.4)$ & 127,713 \\
\hline \multicolumn{9}{|l|}{ Race/ethnicity } \\
\hline White, NH & $65.4(65.0-65.7)$ & 252,748 & $63.7(61.3-66.0)$ & 5410 & $60.0(57.2-62.7)$ & 3455 & $63.0(62.6-63.3)$ & 304,640 \\
\hline Black, NH & $11.1(10.9-11.4)$ & 22,637 & $10.4(9.0-12.0)$ & 444 & $11.2(9.6-12.9)$ & 384 & $11.7(11.5-11.9)$ & 29,632 \\
\hline Hispanic & $15.5(15.2-15.8)$ & 21,572 & $17.1(15.2-19.3)$ & 656 & $18.2(15.7-21.0)$ & 461 & $16.8(16.5-17.1)$ & 30,508 \\
\hline Other race, $\mathrm{NH}$ & $6.6(6.4-6.8)$ & 17,013 & $6.7(5.3-8.5)$ & 332 & $8.0(6.7-9.5)$ & 339 & $7.1(6.9-7.3)$ & 22,362 \\
\hline Multiracial, NH & $1.4(1.4-1.5)$ & 7875 & $2.1(1.6-2.7)$ & 229 & $2.6(2.0-3.4)$ & 191 & $1.4(1.4-1.5)$ & 9608 \\
\hline \multicolumn{9}{|l|}{ Education } \\
\hline $\begin{array}{l}\text { Less than } \\
\text { high school }\end{array}$ & $13.4(13.1-13.7)$ & 23,147 & $6.9(5.8-8.2)$ & 301 & $14.8(12.6-17.3)$ & 414 & $14.3(14.0-14.5)$ & 31,447 \\
\hline $\begin{array}{l}\text { High school } \\
\text { graduate }\end{array}$ & $30.2(29.9-30.6)$ & 91,452 & $22.9(20.8-25.1)$ & 1285 & $29.4(27.1-31.8)$ & 1406 & $29.8(29.5-30.1)$ & 112,989 \\
\hline Some college & $29.9(29.5-30.2)$ & 84,342 & $32.3(30.2-34.5)$ & 1794 & $33.6(31.1-36.3)$ & 1370 & $29.1(28.8-29.4)$ & 102,507 \\
\hline $\begin{array}{l}\text { College } \\
\text { graduate }\end{array}$ & $26.5(26.2-26.8)$ & 127,766 & $37.9(36.0-39.9)$ & 3755 & $22.2(20.5-24.1)$ & 1728 & $26.9(26.6-27.1)$ & 157,038 \\
\hline \multicolumn{9}{|l|}{ Income level } \\
\hline$<\$ 15 \mathrm{~K}$ & $7.9(7.7-8.1)$ & 20,804 & $11.4(10.0-13.0)$ & 674 & $11.9(10.2-13.8)$ & 516 & $8.5(8.3-8.7)$ & 26,984 \\
\hline$\$ 15,000-24,999$ & $14.2(13.9-14.4)$ & 38,010 & $15.5(13.8-17.4)$ & 1004 & $21.2(18.7-23.9)$ & 836 & $15.1(14.8-15.3)$ & 48,732 \\
\hline$\$ 25,000-34,999$ & $9.7(9.4-9.9)$ & 27,822 & $8.7(7.5-10.0)$ & 597 & $12.8(10.9-15.0)$ & 504 & $9.9(9.7-10.1)$ & 34,296 \\
\hline$\$ 35,000-49,999$ & $13.8(13.5-14.0)$ & 40,517 & $13.6(11.9-15.5)$ & 881 & $13.6(11.9-15.4)$ & 607 & $13.5(13.3-13.8)$ & 48,715 \\
\hline$\$ 50 \mathrm{~K}+$ & $54.5(54.1-54.9)$ & 160,521 & $50.8(48.5-53.2)$ & 3362 & $40.5(37.7-43.3)$ & 1813 & $53.0(52.7-53.3)$ & 189,782 \\
\hline \multicolumn{9}{|l|}{ Relationship status } \\
\hline Married & $54.1(53.7-54.4)$ & 187,951 & $19.5(18.0-21.2)$ & 1530 & $27.5(25.3-29.9)$ & 1498 & $52.0(51.7-52.3)$ & 224,679 \\
\hline Divorced & $10.2(10.0-10.3)$ & 41,765 & $5.8(4.9-6.9)$ & 507 & $7.8(6.5-9.2)$ & 626 & $9.8(9.6-10.0)$ & 50,303 \\
\hline Widowed & $3.6(3.5-3.8)$ & 20,879 & $1.9(1.5-2.5)$ & 222 & $3.1(2.4-3.9)$ & 265 & $3.4(3.3-3.5)$ & 24,844 \\
\hline Separated & $2.2(2.1-2.3)$ & 6304 & $1.1(0.8-1.5)$ & 83 & $2.4(1.7-3.4)$ & 131 & $2.3(2.2-2.4)$ & 8072 \\
\hline Never married & $25.5(25.1-25.8)$ & 58,943 & $58.9(56.7-61.0)$ & 3897 & $51.4(48.7-54.0)$ & 2062 & $27.6(27.3-27.9)$ & 80,693 \\
\hline $\begin{array}{l}\text { Member } \\
\text { of unmarried } \\
\text { couple }\end{array}$ & $4.5(4.3-4.6)$ & 10,142 & $12.7(11.3-14.4)$ & 874 & $7.9(6.7-9.3)$ & 318 & $4.9(4.8-5.1)$ & 14,172 \\
\hline
\end{tabular}

The sample was restricted to states that used the SOGI module, which included: CA, CO, CT, DE, FL, GA, HI, ID, IL, IN, IA, KS, KY, LA, MD, MA, MN, MS, MO, MT, NV, NY, NC, OH, OK, PA, RI, SC, TN, TX, VT, VA, WA, WI, and WV.

${ }^{\mathrm{a}}$ Unweighted sample size.

A 10-percentage point increase in the APS score was associated with 0.96 (95\% confidence interval [CI]: 0.94-0.99, $p=0.003$ ) odds of binge drinking among women from 2015 to 2018 after accounting for individual characteristics, state-level characteristics, state enforcement capacity, state geography, and survey year (Table 4). Lesbian women had 1.43 (95\% CI: $1.17-1.75, p<0.001)$ times the odds of binge drinking compared with heterosexual women adjusting for state APS score, individual characteristics, state-level characteristics, state enforcement capacity, state geography, and survey year. Bisexual women had 1.58 (95\% CI: $1.40-1.79, p<0.001)$ times the odds of binge drinking compared with heterosexual women adjusting for state APS score, individual characteristics, state-level characteristics, state enforcement capacity, state geography, and survey year.

The interaction between state APS score and sexual identity was not statistically significant among men (gay: $p=0.670$; bisexual: $p=0.723$ ). Among men, a 10-percentage point increase in the APS score was not associated with binge drinking odds from 2015 to 2018 after accounting for individual characteristics, state-level characteristics, state enforcement capacity, state geography, and survey year (odds ratio [OR]: 1.00, 95\% CI: 0.97-1.02, $p=0.706$ ) (Table 5). Gay men had 1.03 (95\% CI: $0.91-1.17, p=0.627$ ) times the odds of binge drinking compared with heterosexual men after adjusting for state APS score, individual 


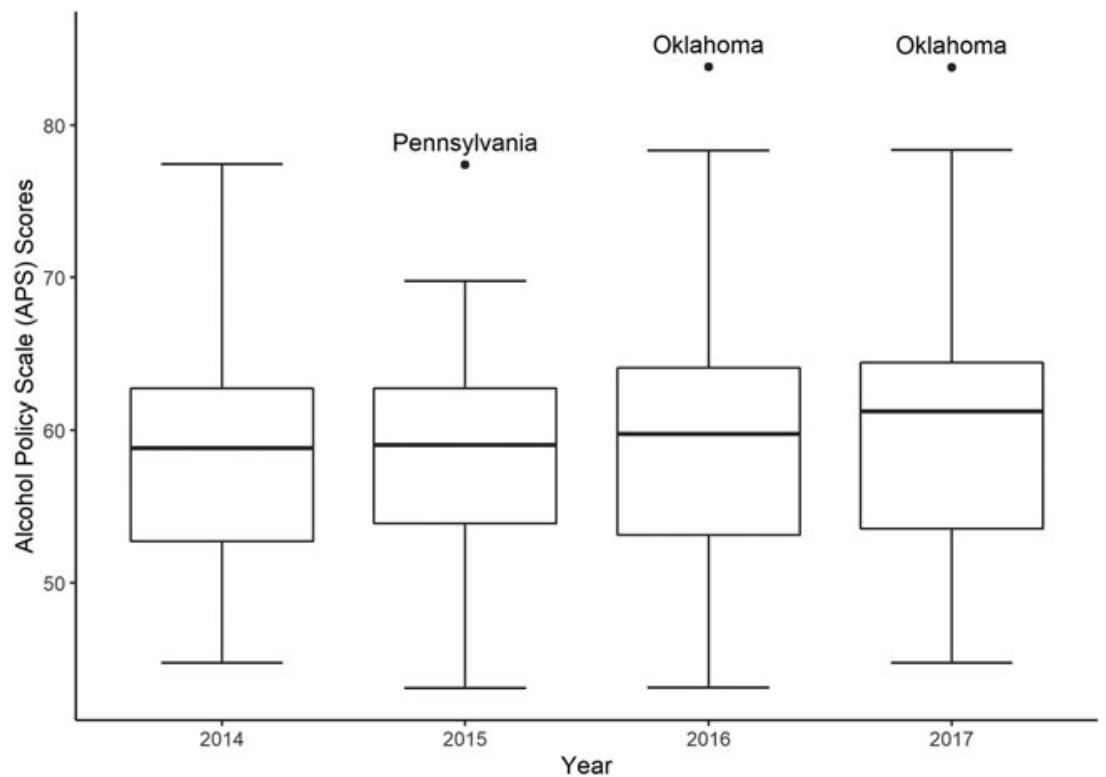

FIG. 1. Distribution of Alcohol Policy Scale scores, 2014-2017. characteristics, state-level characteristics, state enforcement capacity, state geography, and survey year. However, this association was not statistically significant. Bisexual men had 1.03 (95\% CI: $0.88-1.22, p=0.681$ ) times the odds of binge drinking compared with heterosexual men after adjusting for state APS score, individual characteristics, state-level characteristics, state enforcement capacity, state geography, and survey year.

\section{Discussion}

We examined the association between the alcohol policy environment, sexual identity, and individual-level binge drinking and found support for our hypothesis that the alcohol policy environment has the same association with binge drinking for lesbian and bisexual women and heterosexual women as well as for gay and bisexual men and heterosexual men. Stronger and more comprehensive alcohol policy environments were associated with lower odds of binge drinking among women but were not associated with binge drinking among men regardless of sexual identity. Moreover, we found that stronger alcohol policy environments were not associated with narrower differences in binge drinking between lesbian/bisexual and heterosexual women. In other words, after accounting for the strength of the alcohol policy environment and other individual and state-level factors,

Table 3. Descriptive Statistics for Alcohol Policy SCALE SCORES, 2014-2017

\begin{tabular}{lccccc}
\hline & 2014 & 2015 & 2016 & 2017 & $2014-2017$ \\
\hline$N$ & 21 & 25 & 27 & 28 & 35 \\
Mean & 58.5 & 58.6 & 59.3 & 60.8 & 59.4 \\
Standard deviation & 7.96 & 7.89 & 9.50 & 9.78 & 8.82 \\
Minimum & 44.7 & 43.1 & 43.1 & 44.8 & 43.1 \\
Q25 & 52.7 & 53.9 & 53.1 & 53.5 & 52.7 \\
Median & 58.5 & 59.0 & 59.8 & 61.3 & 59.4 \\
Q75 & 62.7 & 62.7 & 64.1 & 64.4 & 63.4 \\
Maximum & 77.4 & 77.4 & 83.8 & 83.8 & 83.8 \\
\hline
\end{tabular}

higher odds of binge drinking among lesbian/bisexual women compared with heterosexual women remained.

We applied a multiple testing correction to our alpha value to reduce the possibility of finding significant results due to chance and constructed $99 \%$ CIs around the point estimates (Supplementary Tables S2 and S3). Overall, point estimates that were significant at $\alpha=0.05$ remained significant at the Bonferroni-corrected $\alpha=0.00625$ with two notable exceptions. First, among women, the point estimate for the association between alcohol policy score and binge drinking adjusted for only state-level covariates was not significant at the Bonferroni-corrected alpha value. This may suggest that there was residual confounding in the model that only included state-level factors given that this point estimate was significant when accounting for all covariates.

Second, our main analyses showed significantly higher odds of binge drinking comparing bisexual with heterosexual men in the model that only included alcohol policy score and survey year. This point estimate is not considered significant using the Bonferroni-adjusted alpha value. However, both the main analyses and the analyses adjusting for the multiple testing correction provide evidence that this point estimate is confounded and that there are no significantly different odds of binge drinking by sexual identity among men after accounting for possible confounding measured at the individual and state level.

Our point estimates for the association between binge drinking and sexual identity among women are quite similar to a previous study using the BRFSS despite accounting for the alcohol policy environment. ${ }^{45}$ These differences can be considered "disparities" because, as noted in the introduction, they are determined by social differences in treatment between lesbian/bisexual and heterosexual women, namely the additional stress that results from homophobia and discrimination. ${ }^{12,46}$

The study findings point to the importance of including a health equity perspective when examining the role of alcohol policy in binge drinking. One literature review found that many studies assume that alcohol policies will have the same effect on alcohol consumption and alcohol-related 
Table 4. Association between Alcohol Policy Score, Sexual Identity, and Individual-Level Binge Drinking Among Women, 2015-2018

\begin{tabular}{|c|c|c|c|c|c|c|c|c|}
\hline & Model 1 & & Model 2 & \multirow[b]{2}{*}{$\mathrm{p}$} & \multirow{2}{*}{$\frac{\text { Model } 3}{\text { OR }}$} & \multirow[b]{2}{*}{$\mathrm{p}$} & Model 4 & \multirow[b]{2}{*}{$\mathrm{p}$} \\
\hline & $\begin{array}{c}\text { OR } \\
(95 \% C I)\end{array}$ & $\mathrm{p}$ & $\begin{array}{c}\text { OR } \\
(95 \% C I)\end{array}$ & & & & $\begin{array}{c}O R \\
(95 \% C I)\end{array}$ & \\
\hline Lesbian & $\begin{array}{c}2.05 \\
(1.72-2.44)\end{array}$ & $<0.001^{*, \dagger}$ & $\begin{array}{c}2.06 \\
(1.73-2.45)\end{array}$ & $<0.001^{*, \dagger}$ & $\begin{array}{c}1.42 \\
(1.17-1.74)\end{array}$ & $<0.001 *, \dagger$ & $\begin{array}{c}1.43 \\
(1.17-1.75)\end{array}$ & $<0.001 *, \dagger$ \\
\hline Bisexual & $\begin{array}{c}2.62 \\
(2.36-2.90)\end{array}$ & $<0.001 *, \dagger$ & $\begin{array}{c}2.60 \\
(2.34-2.88)\end{array}$ & $<0.001^{*, \dagger}$ & $\begin{array}{c}1.59 \\
(1.41-1.79)\end{array}$ & $<0.001^{*, \dagger}$ & $\begin{array}{c}1.58 \\
(1.40-1.79)\end{array}$ & $<0.001 *, \dagger$ \\
\hline Heterosexual & Reference & & & & & & & \\
\hline $\begin{array}{l}\text { APS score } \\
\text { (10 percentage } \\
\text { points) }\end{array}$ & $\begin{array}{c}0.98 \\
(0.95-1.00)\end{array}$ & 0.051 & $\begin{array}{c}0.97 \\
(0.95-0.99)\end{array}$ & $0.012 *$ & $\begin{array}{c}0.93 \\
(0.91-0.96)\end{array}$ & $<0.001^{*}, \dagger$ & $\begin{array}{c}0.96 \\
(0.94-0.99)\end{array}$ & $0.003^{*, \dagger}$ \\
\hline
\end{tabular}

States included in the models: CA, CO, CT, DE, FL, GA, HI, ID, IL, IN, IA, KS, KY, LA, MD, MA, MN, MS, MO, MT, NV, NY, NC, OH, OK, PA, RI, SC, TN, TX, VT, VA, WA, WI, and WV. Model 1: Adjusted for survey year. Model 2: Adjusted for survey year, population age $21+$ years, male population 18+ years, proportion of population White, percent population LGB, median household income, officers per capita, Catholic adherents per 1000 population, percent population living in urban areas, and state region. Model 3: Adjusted for survey year, age, race, income, education, and relationship status. Model 4: Adjusted for survey year, population age 21+ years, male population 18+ years, proportion of population White, percent population LGB, median household income, officers per capita, Catholic adherents per 1000 population, percent population living in urban areas, state region, age, race, income, education, and relationship status.

*Significant at $\alpha=0.05$.

†Significant at $\alpha=0.00625$ (Bonferroni correction where $\alpha=0.05 / n$ where $n=8$, the total number of models in the analysis).

APS, Alcohol Policy Scale; LGB, lesbian, gay, and bisexual; OR, odds ratio.

outcomes across subpopulations, but they do not examine whether this assumption is true or whether these policies can reduce known health disparities (e.g., increased binge drinking among sexual minority adults). ${ }^{4}$ Our findings suggest that, at the very least, the alcohol policy environment does not widen binge drinking disparities between lesbian/ bisexual and heterosexual women in the United States, but stronger alcohol policy environments also do not narrow binge drinking disparities between these groups. Our findings, combined with this understanding of how binge drinking differences between lesbian/bisexual women and heterosexual women occur, underscore that other structural factors, such as nondiscrimination laws, may play an important role.
Moreover, our findings may support current theories of bisexual specific stressors. Similar to a previous study using BRFSS data, ${ }^{45}$ our estimate of the binge drinking disparities between bisexual and heterosexual women is higher than that comparing lesbian and heterosexual women. A recent study examining bisexual women's alcohol use and descriptive drinking norms found that bisexual women believe that other bisexual women drink more than lesbian women. ${ }^{48}$ Moreover, bisexual women's frequency of alcohol consumption, number of binge drinking episodes, and hazardous alcohol use as measured by AUDIT were significantly associated with these descriptive drinking norms for bisexual women, but not descriptive drinking norms for lesbian or heterosexual women. ${ }^{48}$ In addition, a previous study has

Table 5. Association between Alcohol Policy Score, Sexual Identity, and Individual-Level Binge Drinking Among Men, 2015-2018

\begin{tabular}{|c|c|c|c|c|c|c|c|c|}
\hline & Model 1 & & Model 2 & \multirow[b]{2}{*}{$\mathrm{p}$} & \multirow{2}{*}{$\frac{\text { Model } 3}{\text { OR }}$} & \multirow[b]{2}{*}{$p$} & Model 4 & \multirow[b]{2}{*}{$\mathrm{p}$} \\
\hline & $\begin{array}{c}\text { OR } \\
(95 \% C I)\end{array}$ & $\mathrm{p}$ & $\begin{array}{c}\text { OR } \\
(95 \% C I)\end{array}$ & & & & $\begin{array}{c}O R \\
(95 \% C I)\end{array}$ & \\
\hline Gay & $\begin{array}{c}1.25 \\
(1.12-1.41)\end{array}$ & $<0.001^{*, \dagger}$ & $\begin{array}{c}1.26 \\
(1.24-1.41)\end{array}$ & $<0.001 *, \dagger$ & $\begin{array}{c}1.02 \\
(0.90-1.15)\end{array}$ & 0.737 & $\begin{array}{c}1.03 \\
(0.91-1.17)\end{array}$ & 0.627 \\
\hline Bisexual & $\begin{array}{c}1.26 \\
(1.10-1.44)\end{array}$ & $0.01 *$ & $\begin{array}{c}1.25 \\
(1.09-1.44)\end{array}$ & $0.001 *, \dagger$ & $\begin{array}{c}1.03 \\
(0.88-1.21)\end{array}$ & 0.706 & $\begin{array}{c}1.03 \\
(0.88-1.22)\end{array}$ & 0.681 \\
\hline Heterosexual & Reference & & & & & & & \\
\hline $\begin{array}{l}\text { APS score } \\
\text { (10 percentage points) }\end{array}$ & $\begin{array}{c}0.98 \\
(0.97-1.00)\end{array}$ & 0.115 & $\begin{array}{c}0.99 \\
(0.97-1.01)\end{array}$ & 0.311 & $\begin{array}{c}0.98 \\
(0.96-1.00)\end{array}$ & 0.078 & $\begin{array}{c}1.00 \\
(0.97-1.02)\end{array}$ & 0.706 \\
\hline
\end{tabular}

States included in the models: CA, CO, CT, DE, FL, GA, HI, ID, IL, IN, IA, KS, KY, LA, MD, MA, MN, MS, MO, MT, NV, NY, NC, OH, OK, PA, RI, SC, TN, TX, VT, VA, WA, WI, and WV. Model 1: Adjusted for survey year. Model 2: Adjusted for survey year, population age $21+$ years, male population 18+ years, proportion of population White, percent population LGB, median household income, officers per capita, Catholic adherents per 1000 population, and state region. Model 3: Adjusted for survey year, age, race, income, education, and relationship status. Model 4: Adjusted for survey year, population age 21+ years, male population 18+ years, proportion of population White, percent population LGB, median household income, officers per capita, Catholic adherents per 1000 population, state region, age, race, income, education, and relationship status.

*Significant at $\alpha=0.05$.

${ }^{\dagger}$ Significant at $\alpha=0.00625$ (Bonferroni correction where $\alpha=0.05 / n$ where $n=8$, the total number of models). 
shown that both heterosexual and lesbian/gay individuals hold negative attitudes toward bisexual individuals such as beliefs about hypersexuality, immorality, and being confused about one's sexuality. ${ }^{49}$ A 2016 study with a nationally representative sample of U.S. adults found that, since the passage of marriage equality, while attitudes toward lesbian women and gay men were becoming more positive, most adults had neutral or negative attitudes about bisexual individuals. $^{50}$

Our findings also have implications for future research on how alcohol policies may be related to differences in alcohol consumption between women and men across sexual identity. Higher APS scores reflect that a state enacted and fully implemented several highly efficacious alcohol policies. These include (1) higher taxes on alcohol products, particularly those that are a function of price rather than volume; (2) state monopoly on alcohol products; and (3) bans on alcohol sales during certain days or times. ${ }^{51}$ These policies are related to either the affordability or physical availability of alcohol in a state. The fact that we found a significant association between the alcohol policy environment for women, but not men may be due to differences in socioeconomic position and place of alcohol consumption between women and men by sexual identity.

Sexual minority populations are diverse across other demographic characteristics, including socioeconomic position. This study shows that a large proportion of lesbian and bisexual women have lower household incomes in comparison with both heterosexual women and heterosexual, gay, and bisexual men. Although individuals at higher income levels are more likely to binge drink and have more binge drinking episodes, those at lower levels of income have more drinks per binge (i.e., high binge drinking intensity). ${ }^{52}$ Previous evidence supports that sexual minority women are more likely to engage in high-intensity binge drinking, defined as $8+$ drinks in a single day, compared with heterosexual women. ${ }^{7}$ Thus, a logical next step would be to examine policies that influence the price of alcohol and their association with binge drinking by sex and sexual orientation. Further, questions remain about how placebased alcohol policies may affect sexual minority and heterosexual women and men. Population-based survey data show that heterosexual women spend less time in bars and at parties compared with lesbian, bisexual, and other sexual minority women, and gay and bisexual men spend more time in bars and at parties compared with heterosexual men. ${ }^{53}$ Therefore, alcohol outlet density and other place-based policies (e.g., days/hours of sale, prohibition of sales to intoxicated patrons) may have differential relationships with binge drinking and other alcohol-related outcomes across sex and sexual identity because of these differences in how often individuals spend drinking in public and semi-public locations. Interrogating how place-based alcohol policies are related to binge drinking differences by sex and binge drinking disparities by sexual orientation is another important next step for future research.

\section{Limitations}

Our findings should be interpreted in the context of several limitations. Our data are limited in making causal arguments about the association between the alcohol policy environ- ment and binge drinking. Although this study only found a significant association between the alcohol policy environment and binge drinking for women, a previous study found small significant protective effects for the alcohol policy environment among women, men, and the general population. ${ }^{21}$ Because the SOGI module is not used in all 50 states, our sample size may not have been adequate to detect significance for a small estimated association for men. Despite this limitation, our study found that disparities in binge drinking across sexual identity persist, particularly among lesbian and bisexual women, even when accounting for strictness of the alcohol policy environment.

Although the analysis included multiple years of data, the variability in APS scores was primarily between states within each year rather than within states across years. However, our models lagged APS scores by 1 year to ensure that binge drinking was measured after the implementation of new alcohol laws, thus creating some temporal ordering between our exposure and outcome. The lagged APS score also helps to reduce the possibility of reverse causation in which stronger alcohol policy laws are implemented because of lower binge drinking prevalence in the state- a function of public attitudes about alcohol consumption. Although the APS score is superior in measuring the combined strength of individual alcohol policies enacted and implemented in the state, the APS score on its own does not provide insights into which specific policy or policies have which impacts.

Although we adjusted for baseline differences between individuals and states, there is still the potential for unmeasured confounding. Moreover, by combining 4 years of survey data and including survey year as a covariate in the models, we are assuming that individuals are exchangeable across both state and time. Although our study period comes after the national recognition of marriage equality, a major victory for LGBT equality, there may be other secular trends in cultural and social norms in how LGBT communities are treated that are not accounted for in our models that could impact binge drinking.

Although the sampling methodology makes our results generalizable to the states from which individuals were selected and provides state-level prevalence estimates for health behaviors, our findings are not generalizable nationally because the SOGI module is not currently in use by all 50 states. However, our exploratory analyses showed that the states that were included in the analyses did not differ significantly on alcohol policy score, proportion of LGB population, and binge drinking (Supplementary Tables S4-S6).

Finally, individuals are known to underreport their alcohol use in government surveys. Comparisons between alcohol sales data and the reported prevalence of alcohol use in the BRFSS suggest that survey data account for, on average, $32 \%$ of alcohol consumption in states. ${ }^{54}$ Therefore, the measures of association in this analysis may be biased toward the null because the underestimation of alcohol consumption may lead to classifying some individuals as non-binge drinkers when, in fact, they do engage in this behavior. Moreover, an estimated $30 \%$ of gay and bisexual men report that they would not disclose their sexual orientation on a government survey. ${ }^{55}$ Therefore, the sexual minority men identified in the BRFSS may not be representative of the target population, which can lead to biased inferences about differences in binge drinking prevalence between sexual minority and heterosexual men. 


\section{Conclusion}

Inclusion of the SOGI module on all state's BRFSS surveys would allow researchers to further elucidate the relationship between the alcohol policy environment and binge drinking as well as provide greater insights into sexual and gender minority health. Similar analyses are warranted to assess these outcomes for gender minority populations as well. Future alcohol policy research should examine potential differences in the association between the policy environment and individual policies and binge drinking and other alcoholrelated outcomes across all facets of sexual orientation (e.g., attraction, behavior, and identity). Further, it is critical to investigate whether alcohol policy can reduce disparities, as a primary question. This information can guide policy efforts to reduce binge drinking disparities.

\section{Authors' Contributions}

N.G. conceived and designed the analysis, performed the analysis, and wrote the first draft of the article. All authors contributed to the evolution of the research goals and aims, reviewed and edited article drafts, and approved the final version of the article.

\section{Acknowledgments}

The authors thank Dr. Tim Naimi, Jason Blanchette, and Dr. Ziming Xuan at Boston University for the APS score data.

\section{Disclaimer}

The BRFSS is a publicly available dataset. Data are collected by state health departments and other state public/ private entities. Data collection is overseen by the CDC. The content is solely the responsibility of the authors and does not necessarily represent the official views of the CDC.

\section{Author Disclosure Statement}

No competing financial interests exist.

\section{Funding Information}

Naomi Greene was supported by the National Cancer Institute National Research Service Award T32 CA009314.

\section{Supplementary Material}

Supplementary Table S1

Supplementary Table S2

Supplementary Table S3

Supplementary Table S4

Supplementary Table S5

Supplementary Table S6

\section{References}

1. Centers for Disease Control and Prevention. BRFSS Web Enabled Analysis Tool. Available at https://nccd.cdc.gov/ weat/\#/crossTabulation/viewReport Accessed September $10,2020$.
2. National Institute on Alcohol Abuse and Alcoholism. Drinking levels defined. Available at https://www.niaaa .nih.gov/alcohol-health/overview-alcohol-consumption/mod erate-binge-drinking Accessed September 14, 2020.

3. World Health Organization: Global Status Report on Alcohol and Health 2018. Geneva, Switzerland: WHO, 2018.

4. Wilsnack RW, Wilsnack SC, Gmel G, Kantor LW: Gender differences in binge drinking prevalence, predictors, and consequences. Alcohol Res Curr Rev 2018;39:57-76.

5. Dawson DA, Goldstein RB, Saha TD, Grant BF: Changes in alcohol consumption: United States, 2001-2002 to 20122013. Drug Alcohol Depend 2015;148:56-61.

6. Medley G, Lipari RN, Bose J, et al.: Sexual Orientation and Estimates of Adult Substance Use and Mental Health: Results from the 2015 National Survey on Drug Use and Health. NSDUH Data Review. 2016. Available at https:// www.samhsa.gov/data/sites/default/files/NSDUH-Sexual Orientation-2015/NSDUH-SexualOrientation-2015/NSDUHSexualOrientation-2015.htm Accessed December 14, 2020.

7. Fish JN: Sexual orientation-related disparities in highintensity binge drinking: Findings from a nationally representative sample. LGBT Health 2019;6:242-249.

8. Gonzales G, Przedworski J, Henning-Smith C: Comparison of health and health risk factors between lesbian, gay, and bisexual adults and heterosexual adults in the United States: Results from the National Health Interview Survey. JAMA Intern Med 2016;176:1344-1351.

9. Drabble L, Midanik LT, Trocki K: Reports of alcohol consumption and alcohol-related problems among homosexual, bisexual and heterosexual respondents: Results from the 2000 National Alcohol Survey. J Stud Alcohol 2005;66: 111-120.

10. Hughes TL, Wilsnack SC, Kantor LW: The influence of gender and sexual orientation on alcohol use and alcoholrelated problems: Toward a global perspective. Alcohol Res 2016;38:121-132.

11. Wray TB, Pantalone DW, Kahler CW, et al.: The role of discrimination in alcohol-related problems in samples of heavy drinking HIV-negative and positive men who have sex with men (MSM). Drug Alcohol Depend 2016;166: 226-234.

12. Wilson SM, Gilmore AK, Rhew IC, et al.: Minority stress is longitudinally associated with alcohol-related problems among sexual minority women. Addict Behav 2016;61: 80-83.

13. Drabble L, Trocki KF, Hughes TL, et al.: Sexual orientation differences in the relationship between victimization and hazardous drinking among women in the National Alcohol Survey. Psychol Addict Behav 2013;27:639-648.

14. Hughes TL, Szalacha LA, Johnson TP, et al.: Sexual victimization and hazardous drinking among heterosexual and sexual minority women. Addict Behav 2010;35:11521156.

15. Feinstein BA, Bird ER, Fairlie AM, et al.: A descriptive analysis of where and with whom lesbian versus bisexual women drink. J Gay Lesbian Ment Health 2017;21: 316-326.

16. Tobin KE, Latkin CA, Curriero FC: An examination of places where African American men who have sex with men (MSM) use drugs/drink alcohol: A focus on social and spatial characteristics. Int J Drug Policy 2014;25:591597. 
17. Cogger A, Conover KJ, Israel T: Factors influencing alcohol use among sexual minority women in a non-urban community: A mixed methods study. J LGBT Issues Couns 2012;6: 293-309.

18. Emslie C, Lennox J, Ireland L: The role of alcohol in identity construction among LGBT people: A qualitative study. Sociol Health Illn 2017;39:1465-1479.

19. Drabble L, Trocki K: Alcohol in the life narratives of women: Commonalities and differences by sexual orientation. Addict Res Theory 2014;22:186-194.

20. Naimi TS, Blanchette J, Nelson TF, et al.: A new scale of the U.S. alcohol policy environment and its relationship to binge drinking. Am J Prev Med 2014;46:10-16.

21. Xuan Z, Blanchette J, Nelson TF, et al.: The alcohol policy environment and policy subgroups as predictors of binge drinking measures among US adults. Am J Public Health 2015;105:816-822.

22. Xuan Z, Blanchette JG, Nelson TF, et al.: Youth drinking in the United States: Relationships with alcohol policies and adult drinking. Pediatrics 2015;136:18-27.

23. Babor T, Caetano R, Casswell S, et al:: Alcohol: No Ordinary Commodity: Research and Public Policy, 2nd ed. New York, NY: Oxford University Press, 2010.

24. Elder RW, Lawrence B, Ferguson A, et al.: The effectiveness of tax policy interventions for reducing excessive alcohol consumption and related harms. Am J Prev Med 2010;38:217-229.

25. Campbell CA, Hahn RA, Elder R, et al.: The effectiveness of limiting alcohol outlet density as a means of reducing excessive alcohol consumption and alcohol-related harms. Am J Prev Med 2009;37:556-569.

26. Middleton JC, Hahn RA, Kuzara JL, et al.: Effectiveness of policies maintaining or restricting days of alcohol sales on excessive alcohol consumption and related harms. Am J Prev Med 2010;39:575-589.

27. Subbaraman MS, Mulia N, Kerr WC, et al.: Relationships between US state alcohol policies and alcohol outcomes: Differences by gender and race/ethnicity. Addiction 2020; 115:1285-1294.

28. Hatzenbuehler ML, Keyes KM, Hamilton A, Hasin DS: State-level tobacco environments and sexual orientation disparities in tobacco use and dependence in the USA. Tob Control 2014;23:e127-e132.

29. Centers for Disease Control and Prevention. The BRFSS Data User Guide. 2013. Available at https://www.cdc .gov/brfss/data_documentation/pdf/UserguideJune2013.pdf Accessed September 14, 2020.

30. Centers for Disease Control and Prevention (CDC): Methodologic changes in the Behavioral Risk Factor Surveillance System in 2011 and potential effects on prevalence estimates. MMWR Morb Mortal Wkly Rep 2012;61: 410-413.

31. Kanny D, Liu Y, Brewer RD, et al.: Binge drinking-United States, 2011. MMWR Suppl 2013;62:77-80.

32. Nelson DE, Naimi TS, Brewer RD, et al.: Metropolitan-area estimates of binge drinking in the United States. Am J Public Health 2004;94:663-671.

33. Xuan Z, Nelson TF, Heeren T, et al.: Tax policy, adult binge drinking, and youth alcohol consumption in the United States. Alcohol Clin Exp Res 2013;37:1713-1719.

34. Holt JB, Miller JW, Naimi TS, Sui DZ: Religious affiliation and alcohol consumption in the United States. Geogr Rev 2006;96:523-542.
35. U.S. Census Bureau. 2011-2015 American Community Survey 5-Year Estimates. 2019. Available at https://www .census.gov/programs-surveys/acs/technical-documentation/ table-and-geography-changes/2015/5-year.html Accessed September 10, 2020.

36. U.S. Census Bureau. 2012-2016 American Community Survey 5-Year Estimates. 2019. Available at https://www .census.gov/programs-surveys/acs/technical-documentation/ table-and-geography-changes/2016/5-year.html Accessed September 10, 2020.

37. U.S. Census Bureau. 2013-2017 American Community Survey 5-Year Estimates. 2018. Available at https://www .census.gov/programs-surveys/acs/technical-documentation/ table-and-geography-changes/2017/5-year.html Accessed September 10, 2020.

38. U.S. Census Bureau. 2018 American Community Survey Single-Year Estimates. 2019. Available at https://www.cen sus.gov/newsroom/press-kits/2019/acs-1year.html Accessed September 10, 2020.

39. Federal Bureau of Investigation. Uniform Crime Reporting (UCR): Crime in the U.S. Available at https://ucr.fbi.gov/ crime-in-the-u.s Accessed September 10, 2020.

40. U.S. Census Bureau. 2010 Census Summary File 1-United States. 2011. Available at https://www.census.gov/data/data sets/2010/dec/summary-file-1.html Accessed September 14, 2020.

41. U.S. Census Bureau. 2010 Census Summary File 1: 2010 Census of Population and Housing: Technical Documentation. 2012. Available at https://www.census .gov/prod/cen2010/doc/sf1.pdf Accessed September 14, 2020 .

42. Grammich C, Hadaway K, Houseal R, et al.: U.S. Religion Census Religious Congregations and Membership Study, 2010 (State File). 2018. Available at http://www.thearda .com/Archive/Files/Descriptions/RCMSST10.asp Accessed October 9, 2019.

43. U.S. Census Bureau. Census regions and divisions of the United States. Available at https://www2.census.gov/geo/ pdfs/maps-data/maps/reference/us_regdiv.pdf Accessed September 10, 2020.

44. Conron KJ, Goldberg SK: Adult LGBT population in the United States. 2019. Available at https://williamsinstitute .law.ucla.edu/wp-content/uploads/LGBT-Adult-US-Pop-Mar2019.pdf Accessed September 14, 2020.

45. Gonzales G, Henning-Smith C: Health disparities by sexual orientation: Results and implications from the Behavioral Risk Factor Surveillance System. J Community Health 2017;42:1163-1172.

46. Meyer IH: Prejudice, social stress, and mental health in lesbian, gay, and bisexual populations: Conceptual issues and research evidence. Psychol Bull 2003;129: 674-697.

47. Roche A, Kostadinov V, Fischer J, et al.: Addressing inequities in alcohol consumption and related harms. Health Promot Int 2015;30(Suppl. 2):ii20-ii35.

48. Ehlke SJ, Stamates AL, Kelley ML, Braitman AL: Bisexual women's reports of descriptive drinking norms for heterosexual, bisexual, and lesbian women. Psychol Sex Orientat Gend Divers 2019;6:256-263.

49. Friedman MR, Dodge B, Schick V, et al.: From bias to bisexual health disparities: Attitudes toward bisexual men and women in the United States. LGBT Health 2014;1: 309-318. 
50. Dodge B, Herbenick D, Friedman MR, et al.: Attitudes toward bisexual men and women among a nationally representative probability sample of adults in the United States. PLoS One 2016;11:e0164430.

51. Nelson TF, Xuan Z, Babor TF, et al.: Efficacy and the strength of evidence of U.S. alcohol control policies. Am J Prev Med 2013;45:19-28.

52. Kanny D, Naimi TS, Liu Y, et al.: Annual total binge drinks consumed by U.S. adults, 2015. Am J Prev Med 2018;54: 486-496.

53. Trocki KF, Drabble L, Midanik LT: Use of heavier drinking contexts among heterosexuals, homosexuals and bisexuals: Results from a National Household Probability Survey. J Stud Alcohol 2005;66:105-110.

54. Nelson DE, Naimi TS, Brewer RD, Roeber J: US state alcohol sales compared to survey data, 1993-2006. Addiction 2010;105:1589-1596.
55. Ferlatte O, Hottes TS, Trussler T, Marchand R: Disclosure of sexual orientation by gay and bisexual men in government-administered probability surveys. LGBT Health 2017;4:68-71.

Address correspondence to: Naomi Greene, PhD, MPH Department of Health, Behavior and Society Bloomberg School of Public Health Johns Hopkins University 624 N. Broadway Baltimore, MD 21205

USA

E-mail: ngreene9@jhmi.edu 